\title{
Design and Engineering Application of Direct Mixing Lubrication System for Emulsion Pipeline in Secondary Cold Rolling Mill
}

\author{
Hangzhe DONG ${ }^{1}$, Yazhen $\mathrm{ZHANG}^{1}$, Wantong $\mathrm{HU}^{1}$,Zhen-hua BAI ${ }^{2 *}$, Yan-yan $\mathrm{ZHANG}^{1^{*}}$
}

1 National Engineering Research Center for Equipment and Technology of Cold Strip Rolling, Yanshan University, Yanshan University, Qinhuangdao, China

2 State Key Laboratory of Metastable Materials Science and Technology, Yanshan University, Qinhuangdao, China

*Corresponding Author: Zhenhua BAI, E-mail: bai_zhenhua@aliyun.com; Yanyan ZHANG, E-mail: ysuzhang2020@126.com

\begin{abstract}
:
With the benefit fierce competition in the steel industry market in recent years, double cold reduction products have been developed towards strength improvement and thickness reduction. The traditional cold-rolling lubrication process with a fixed flow rate and concentration cannot solve the problems, which are uncontrollable plate shape and the excessive consumption of lubricating oil. Moreover,based on the analysis of the traditional direct aplication lubrication system of double cold reduction mill, a set of design scheme suitable for the emulsion pipeline direct mixing lubrication system of double cold reduction mill unit was proposed.The design completed the selection of key components, which included the static mixer and atomization nozzle selection, pump and oil pump design selection, pipeline design selection, flow type selection, pressure gauge selection, electronic control cabinet design selection and other eight aspects. Equipment of the emulsion pipeline direct mixing lubrication system of double cold reduction has been developed. Comparing with characteristics of the traditional direct aplication lubrication system, the emulsion pipeline direct mixing lubrication system was better applied to the production practice of a 1220 double cold reduction mill. The consumption of ton of steel was reduced by $9.6 \%$. The rolling energy consumption and fuel consumption comprehensive costs decreased by $10.7 \%$, and the strip steel section thickness difference was reduced by $19.3 \%$. In addition, the plate shape quality defect rate decreased by $25.6 \%$, otherwise creating a large economic benefit for the unit and promoting the application value.
\end{abstract}

Keywords: double cold reduction; emulsion; direct mixing lubrication system; static mixer; plate thickness

\section{Introduction}

With the continuous expansion of the market for cans, packaging and other industries, the double cold reduction industry has achieved rapid development ${ }^{[1,2]}$. Simultaneously, downstream users are increasingly demanding the thickness and strength of products to reduce the cost of raw materials and increase the profitability of cans and packaging. For these users, if the thickness of the plate is reduced by half, then the area of the plate is doubled. Therefore, high strength and thinning have become the trend of double cold reduction product development ${ }^{[3]}$. In the double cold reduction process, the traditional direct aplication lubrication system is preconfigured in the mixing tank, and this process spends some time stirring the mixture to achieve the emulsion particle size, ESI(Emulsion stability factor) and other characteristic parameters required for onsite production; accordingly, it cannot be adjusted online in real time. The emulsion concentration and the flow rate during the production of the same coil have nearly no adjustment. Thus, for ultra-thin high-strength double cold reduction products with high rolling stability and high precision of plate shape and thickness control, the conventional flow lubrication process with fixed flow rate and concentration can not meet customer needs, because of rolling pressure with the change of rolling speed and excessive fluctuations, rolling instability, unmanageable plate and thickness, growing oil consumption ${ }^{[4-5]}$. Kimura and Fujita solve the vibration problem of thin strip steel during high-speed rolling by dynamically controlling the flow of direct injection of hybrid-lubrication system ${ }^{[6]}$ Das and his team researched the drop breakage model in static mixers at low and Intermediate reynolds number ${ }^{[7]}$.On the basis of numerous field tests and theoretical studies, a static mixer is applied to the lubrication system of double cold reduction, and the static oil mixer directly mixes the rolling oil with water to replace the original emulsion mixing tank.And developed a emulsion pipeline direct mixing 
lubrication system that is suitable for double cold reduction. This lubrication system, with the online adjustment of the flow rate and concentration, eventually achieves the goal of maximum improvement of rolling stability and reducing fuel consumption. This study will introduce the design principle of the emulsion pipeline direct mixing lubrication system, the selection of key components and the application effect of the project.

\section{Brief introduction of traditional direct aplication lubrication system for double cold reduction}

The traditional direct aplication lubrication system uses a high-concentration, small-flow emulsion, whose concentration is generally $5 \%-15 \%$, and the flow rate is generally lower than $30 \mathrm{~L} / \mathrm{min}$ (see Figure 1). The emulsion is sprayed on the strip surface at a certain distance from the roll gap. The rolling oil droplets in the emulsion are separated from the water and gradually precipitate on the strip surface given the oleophilic hydrophobic property of the strip surface. And oil film provides lubricantion during the rolling process. The emulsion of the direct aplication lubrication system only plays a lubricating role in the rolling process. A special roll cooling system is arranged on the outlet side of the rolling deformation zone, and considerable cooling water is sprayed on the roll surface for cooling. Rolling lubrication and cooling capacity can be adjusted separately ${ }^{[8]}$. The traditional direct aplication lubrication system are discharged directly after use without recycling, thereby resulting in high fuel consumption and waste of substantial emulsion. Therefore, controlling fuel consumption can reduce production costs and environmental pressure.

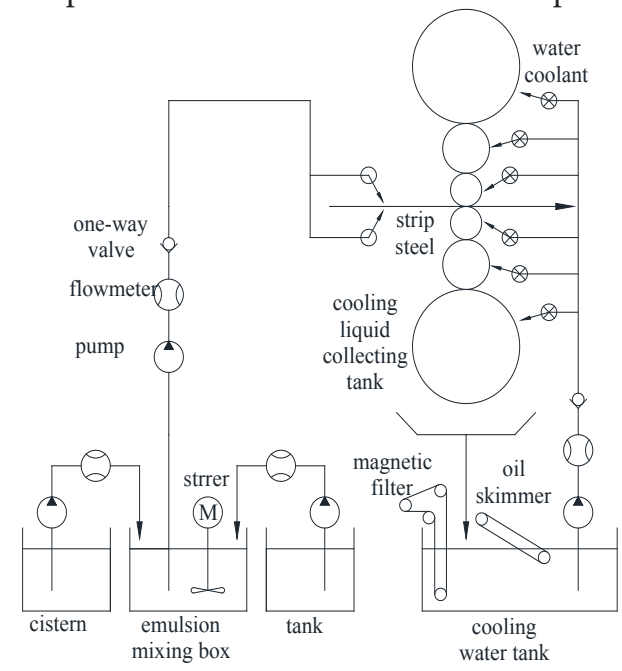

Figure 1 Schematic of the traditional direct application lubrication system.

\section{Design of the emulsion pipeline direct mix- ing lubrication system}

3.1 Design principle of the emulsion pipeline direct mixing lubrication system

A schematic of the emulsion pipeline direct mixing lubrication system of the double cold reduction unit is shown (see Figure 2). During the on-site production process of double cold reduction unit, the deionised water in the pump water tank passes through the water filter, flow metrer and pressure gauge,three-way and one-way valves are sent to the upper and lower static mixing inlets,and controlling the flow of deionized water and rolling oil by adjusting the speed of the pump and oil pump in real time with inverter to achieve the flow and concentration of emulsifiers required to regulate different steel species and rolling speeds. The rolling oil and deionised water are sequentially flowed through the static mixing unit in a static mixer, dispersed and mixed into an emulsion and sprayed on the upper and lower surfaces of the strip through nozzles on the upper and lower spray racks. The emulsion is sprayed on the upper and lower spray racks. Ten emulsion nozzles are installed. The double cold reduction strips and the production gap of the strip, the switching of the opening position of the three-way valve, the selfcirculation of the deionised water and the rolling oil in the pipeline can be realised, and the frequent switching of the water and oil pumps can be avoided.

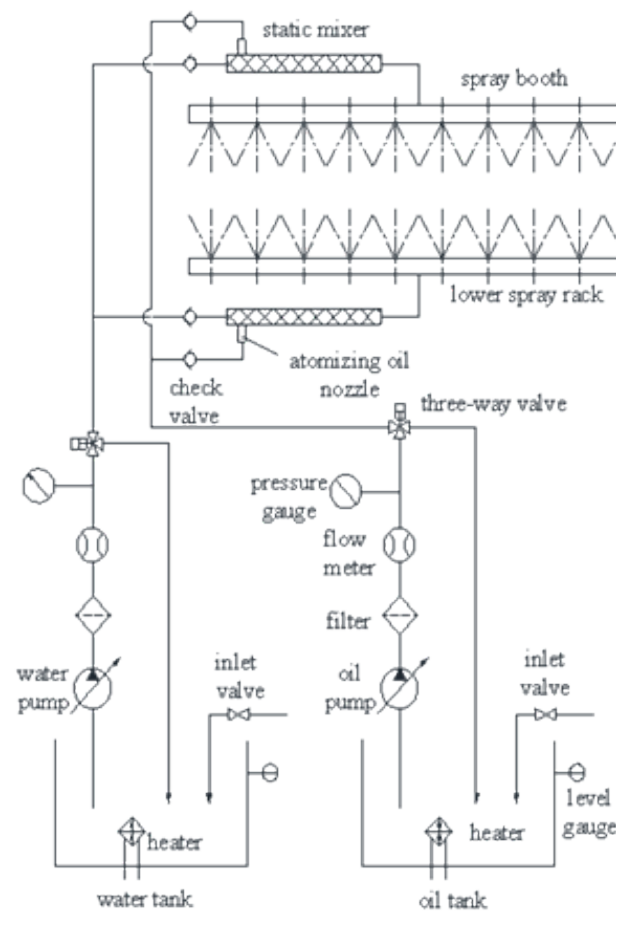

Figure 2 Schematic of the emulsion pipeline direct mixing lubrication system

3.2 Selection of the key components of the emulsion pipeline direct mixing lubrication system for double cold reduction

For the direct mixing lubrication system of double cold reduction, the key components include static mixer, atomising nozzle, water pump, oil pump, pipeline, flow metrer, pressure gauge and electric control cabinet. The result of selection directly determines whether the system can operate normally. 


\subsubsection{Selection of static mixer and atomising nozzle}

The most important component of direct mixing lubrication system is a static mixer. In contrast to conventional agitator devices, despite the lack of moving parts in the static mixer, the initial kinetic energy provided by a momentum source, such as a pump, allows the mixed fluid to pass through a static mixing unit with a special structure. Static mixer dispersed mixing and distributed mixing of fluids of different scales is well achieved over a wide Reynoldsnumbered range. Static mixers can be used in various fluid viscosities and in different flow conditions intermittently and continuously. They can make different fluids achieve uniform mixing because the mixing elements enhance the turbulence during the movement of fluid to split, stretch, rotate and merge, thereby significantly promoting convective and turbulent diffusion and resulting in a perfect radial mixing effect ${ }^{[9,10]}$. To optimise the static mixer type and atomising oil nozzle type of the direct mixing lubrication system of double cold reduction emulsion line, the emulsion particle size and ESI of the direct mixing lubrication system can reach the same performance as the high-speed stirring of the emulsion mixing tank. In combination with the actual working conditions in the on-site production of the emulsion, the injection test is conducted on the experimental device of the direct mixing lubrication system developed. According to the on-site production requirements of the secondary cold rolling mill, the emulsion injection pressure of the injection experiment is set at $5 \mathrm{~kg}$, the emulsion flow rate at $10 \mathrm{~L} / \mathrm{min}$, and the frequency of the oil pump motor at 15,30 and $50 \mathrm{~Hz}$, the emulsion concentration is set at $2 \%-12 \%$, the static mixers with SV, SX and SK types are chosen(see Figure 3). And the atomising oil nozzle comprises 1/4LND types $1 \#, 2 \#$ and 4\# models (see Figure 4). For the direct mixing lubrication system, the emulsion spray test procedure is presented as follows: 1) heating the water and rolling oil in the tank to a temperature of $60^{\circ} \mathrm{C}$ which is commonly applied to the field emulsion; 2) setting the flow rate of the waterway and the oil circuit according to the required emulsion flow rate and concentration; 3 ) adjusting the water and oil flow rates using the return water-regulating valve and the frequency conversion motor, correspondingly; 4) adjusting the emulsion pressure and flow rate through the opening degree of the ball valve on both sides of the emulsion spray frame coordination; 5) recording water pressure and flow, oil pressure and flow and emulsion pressure; 6) emulsion nozzle and leak ball valve position emulsion sampling; 7) using a Multisizer 3 Coulter counter and a particle size analyser to detect emulsion particle diameter (resistance method); 8) detecting emulsion particle size using a BT-9300Z laser particle size distribution analyser (laser method); 9) detecting emulsion concentration using an OHRUS MB35 moisture analyser; 10) using emulsion cylinder and separatory funnel to detect emulsion ESI.In order to ensure the reliability of the experimental data, all the experimental results below are measured multiple times to take their average. a
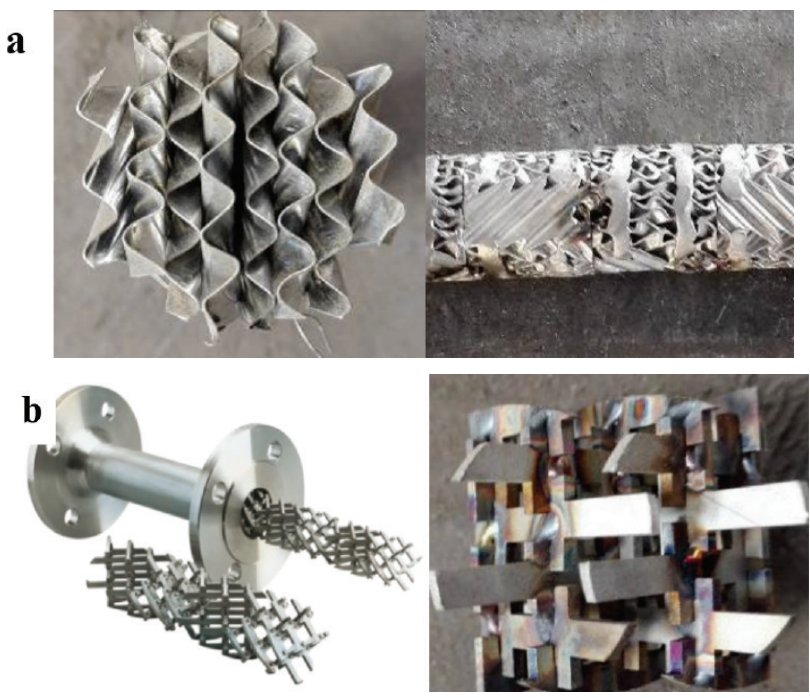

c

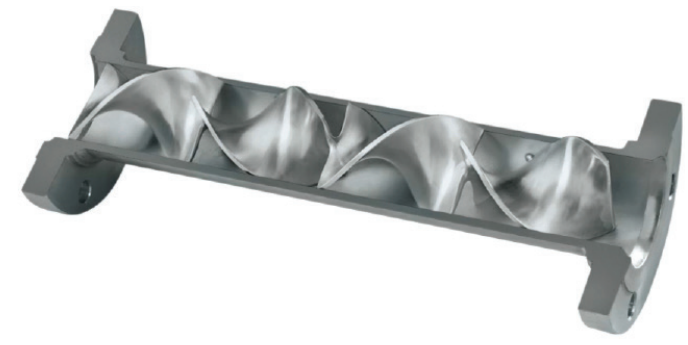

(a) Mixing unit of an SV-type static mixer.(b) Mixing unit of an SX-type static mixer.(c) Mixing unit of an SK-type static mixer.

Figure 3 Element of different static mixers

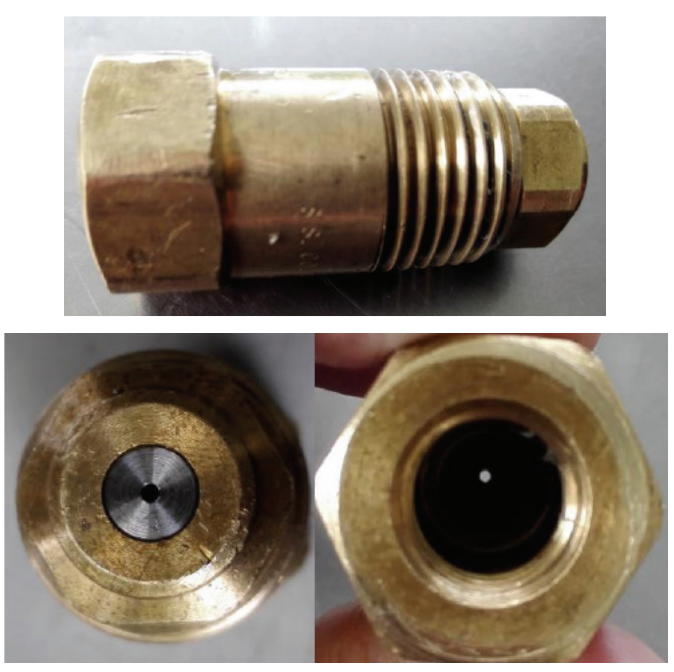

Figure 4 Atomizing oil nozzle

3.2.1.1 Comparison experiment of the different types of static mixers

SV, SX and SK-type static mixers and empty tubes without mixing units are used for comparative experiments to optimise the static mixer selection. The effects of different types of static mixers on emulsion particle size and ESI performance are analysed. Under the condition of the static mixer inlet port does not use the atomising oil nozzle to predisperse the rolling oil, the corresponding static 
pressure of the different static mixers, the concentration of the emulsion, the particle size of the electric resistance method, the particle size of the laser method and the results of ESI test are obtained (see Table 1).

Table 1 Test results of different static mixers

\begin{tabular}{|c|c|c|c|c|c|c|c|c|}
\hline Number & $\begin{array}{l}\text { Static } \\
\text { mixer }\end{array}$ & $\begin{array}{c}\text { Oil } \\
\text { atomizing } \\
\text { sprayer }\end{array}$ & $\begin{array}{c}\text { Oil pump } \\
\text { motor } \\
\text { frequency }(\mathrm{Hz})\end{array}$ & $\begin{array}{c}\text { Oil } \\
\text { pressure } \\
\text { (bar) }\end{array}$ & $\begin{array}{c}\text { Emulsion } \\
\text { concentration } \\
(\%)\end{array}$ & $\begin{array}{c}\text { Resistance } \\
\text { particle size } \\
(\mu \mathrm{m})\end{array}$ & $\begin{array}{c}\text { Laser } \\
\text { particle } \\
\text { size }(\mu \mathrm{m})\end{array}$ & $\begin{array}{l}\text { ESI } \\
(\%)\end{array}$ \\
\hline 1 & & & 15 & 5.0 & 2.65 & 15.05 & 6.885 & 61.9 \\
\hline 2 & Empty tube & Nothing & 30 & 5.0 & 6.62 & 15.84 & 7.642 & 67.4 \\
\hline 3 & & & 50 & 5.0 & 10.42 & 17.76 & 8.657 & 70.76 \\
\hline 4 & & & 15 & 5.0 & 2.38 & 14.95 & 6.523 & 70.17 \\
\hline 5 & SV & Nothing & 30 & 5.0 & 6.24 & 15.02 & 7.552 & 72.96 \\
\hline 6 & & & 50 & 5.0 & 10.74 & 16.68 & 8.471 & 74.27 \\
\hline 7 & & & 15 & 5.0 & 2.48 & 14.02 & 6.343 & 73.47 \\
\hline 8 & SX & Nothing & 30 & 5.0 & 5.83 & 14.42 & 6.538 & 76.67 \\
\hline 9 & & & 50 & 5.0 & 10.41 & 15.50 & 7.237 & 80.12 \\
\hline 10 & & & 15 & 5.0 & 2.48 & 14.38 & 6.650 & 73.79 \\
\hline 11 & SK & Nothing & 30 & 5.0 & 6.11 & 14.72 & 7.051 & 72.83 \\
\hline 12 & & & 50 & 5.0 & & & 10.44 & 16.61 \\
\hline
\end{tabular}

Table 1 displays that, when the static mixer acts alone, with the increase in the frequency of the oil pump motor, the oil flow rate increases, the emulsion concentration increases, the oil line pressure remains unchanged, the emulsion resistance method particle size and the laser particle size diameter increase and the emulsion ESI increase. In comparison with the particle size of the emulsion that corresponds to the empty tube with ESI, the particle size of the emulsion is reduced by the static mixer, and the ESI is increased. The shear dispersion of the oil droplets in the emulsion by the static mixer is beneficial to reducing the particle size of the emulsion. The stability of the emulsion is improved. The emulsions under the action of different static mixers are SX, SK, SV and empty tubes in the order of particle size from small to large. The ESI values of the emulsions are SX, SK, SV and empty tubes in descending order. Therefore, the direct mixing lubrication system for the emulsion line must preferably be an SX-type static mixer to obtain a small emulsion particle size and a large ESI.

3.2.1.2 Comparison experiment of different types of atomised oil nozzles

Experiments are performed with three types of atomising oil nozzles, that is, $1 \#, 2 \#$ and $4 \#$, to analyse the effects of different types of atomising oil nozzles on the particle size and ESI performance of the emulsion for optimising the selection of atomising oil nozzles. Under the condition of not using a static mixer, the corresponding oil pressure, emulsion concentration, electric resistance particle size, laser particle size and ESI test results of different types of oil nozzles are listed (see Table 2).

Table 2 Test results of different atomizing oil nozzles

\begin{tabular}{ccccccccc}
\hline Number & Static mixer & $\begin{array}{c}\text { Oil } \\
\text { atomizing } \\
\text { sprayer }\end{array}$ & $\begin{array}{c}\text { Oil pump } \\
\text { motor } \\
\text { frequency(Hz) }\end{array}$ & $\begin{array}{c}\text { Oil } \\
\text { pressure } \\
\text { (bar) }\end{array}$ & $\begin{array}{c}\text { Emulsion } \\
\text { concentration } \\
(\%)\end{array}$ & $\begin{array}{c}\text { Resistance } \\
\text { particle size } \\
(\mu \mathrm{m})\end{array}$ & $\begin{array}{c}\text { Laser } \\
\text { particle } \\
\text { size } \\
(\mu \mathrm{m})\end{array}$ & $\begin{array}{c}\text { ESI } \\
(\%)\end{array}$ \\
\hline 1 & & & 15 & 5.5 & 2.67 & 15.36 & 6.538 & 78.84 \\
2 & Empty tube & $4 \#$ & 30 & 6.4 & 6.38 & 13.32 & 5.927 & 80.52 \\
3 & & & 50 & 9.2 & 10.74 & 13.23 & 5.791 & 88.68 \\
4 & & & 15 & 6.1 & 1.66 & 14.92 & 5.920 & 82.05 \\
5 & Empty tube & $2 \#$ & 30 & 10.9 & 4.61 & 11.72 & 5.592 & 86.71 \\
6 & & & 50 & 18 & 7.91 & 10.02 & 4.186 & 91.11 \\
7 & & & 15 & 7.5 & 1.29 & 11.84 & 5.206 & 92.25 \\
8 & Empty tube & $1 \#$ & 30 & 16 & 3.76 & 9.741 & 4.561 & 92.29 \\
9 & & & 50 & 26.3 & 5.68 & 7.881 & 3.544 & 93.07 \\
\hline
\end{tabular}

Table 2 reflects that the pressure drop of the rolling oil that passes through the orifice of the atomising oil nozzle determines the effect of atomising and dispersing the rolling oil in water. With the increase in the frequency of the motor, the oil flow rate and the emulsion concentration increase lead to the increasing pressure of ail. With the 
decrease in the diameter of the atomising oil nozzle orifice, the pressure of the oil passage increases remarkably, the particle diameter of the electric resistance of the emulsion and the particle diameter of the laser method decrease and the ESI of the emulsion increases. Simultaneously, with the increase in the oil pressure, the efficiency of the oil pump decreases, and the flow rate of the rolling oil decreases at the same motor frequency, thereby resulting in a decrease in the emulsion concentration. For a specific type of atomising oil nozzle, the increase in emulsion concentration leads to an increase in oil-water pressure difference. However, the oil pressure cannot be increased indefinitely. The selection of atomising oil nozzle requires comprehensive consideration of oil pressure threshold and emulsion particle size.
Therefore, the emulsion pipeline direct mixing lubrication system of double cold reduction mill must preferably be $2 \#$ atomising oil nozzle.

3.2.1.3 Contrast experiment of the different types of static mixer and 2\# atomising oil nozzle

To optimise the selection combination of different types of static mixers and 2\# atomising oil nozzles, different types of static mixers are used with $2 \#$ atomising oil nozzles to conduct the spraying experiment and determine the corresponding oil pressure difference, emulsion concentration, electric resistance particle diameter and laser particle diameter. The ESI detection results are summarised (see Table 3).

Table 3 Test results of different static mixers with 2\# atomizing oil nozzle

\begin{tabular}{ccccccccc}
\hline Number & $\begin{array}{c}\text { Static } \\
\text { mixer }\end{array}$ & $\begin{array}{c}\text { Oil atomizing } \\
\text { sprayer }\end{array}$ & $\begin{array}{c}\text { Oil pump motor } \\
\text { frequency(Hz) }\end{array}$ & $\begin{array}{c}\text { Oil pressure } \\
(\text { bar })\end{array}$ & $\begin{array}{c}\text { Emulsion } \\
\text { concentration } \\
(\%)\end{array}$ & $\begin{array}{c}\text { Resistance } \\
\text { particle size } \\
(\mu \mathrm{m})\end{array}$ & $\begin{array}{c}\text { Laser particle } \\
\text { size }(\mu \mathrm{m})\end{array}$ & $\begin{array}{c}\text { ESI } \\
(\%)\end{array}$ \\
\hline 1 & & & 15 & 6.3 & 1.99 & 14.18 & 5.910 & 83.37 \\
2 & SV & $2 \#$ & 30 & 10.8 & 5.67 & 11.64 & 5.339 & 88.48 \\
3 & & & 50 & 18 & 8.41 & 9.098 & 4.255 & 92.41 \\
4 & & & 15 & 6.1 & 1.74 & 13.11 & 5.657 & 86.21 \\
5 & SX & $2 \#$ & 30 & 11 & 5.52 & 10.63 & 5.289 & 89.68 \\
6 & & & 50 & 18 & 8.5 & 8.105 & 4.103 & 94.88 \\
7 & & & 15 & 6.1 & 1.91 & 14.56 & 5.806 & 84.06 \\
8 & SK & $2 \#$ & 30 & 10.5 & 5.34 & 10.97 & 5.376 & 89.45 \\
9 & & & 50 & 18 & 8.34 & 10.18 & 4.273 & 92.24 \\
\hline
\end{tabular}

Table 3 presents that, under the joint action of different types of static mixers and 2\# atomising oil nozzles, the oil flow rate, emulsion concentration and oil-water pressure difference before and after the oil nozzle increase with the frequency of the oil pump motor. Meanwhile, the emulsion particle size decreases, and ESI increases. In comparison with the 2\# atomising oil nozzle alone, the static mixer can perform secondary shear dispersion on the large particle oil droplets dispersed in the atomising oil nozzle, thus slightly reducing the particle size of the emulsion and increasing the ESI. Among them, the emulsion of the SX static mixer and the 2\# atomising oil nozzle has smaller particles and larger ESI than the synergistic effect of the SK, SX static mixer and the 2\# atomising oil nozzle. Therefore, an SXtype static mixer is recommended to combine with a $2 \#$ atomising oil nozzle.

\subsubsection{Design selection of water and oil pumps}

According to the process characteristics of the emulsion pipeline direct mixing lubrication system of double cold reduction mill, the flow rate of the emulsion in the rolling process must be adjusted rapidly in a wide range, thereby requiring the flow of deionised water and rolling oil rapidly be adjusted over a wide range. And variable pumps are required for water and oil circuits. Simultaneously, the flow rate and concentration of the emulsion during the rolling process must be precisely controlled, and the continuous supply of deionised water and rolling oil must be ensured.
The gear pump is a rotary pump that relies on the change and movement of the working volume formed between the pump cylinder and the meshing gear to transport or pressurise the liquid. The pressure of the discharge port completely depends on the resistance at the pump outlet. Furthermore, the flow is smooth, and the pulsation is small. The utility model has the advantages of simple structure, low price, low maintenance rate, good repeatability and accurate measurement. Therefore, the water and oil pumps must give priority to the gear metering pump. The physical object is demonstrated in Figure 5 (see Figure 5).

In the production process of double cold reduction, the maximum adjustment range of the emulsion flow of the upper and lower spray racks is $5-20 \mathrm{~L} / \mathrm{min}$. According to the technical requirements of water flow $(10-40 \mathrm{~L} / \mathrm{min})$ and pressure (3-10 bar), the pump is $\mathrm{C} 4 / 481$. In addition, a stainless steel gear metering pump, import and export size G1, configuration QABP132S6A 3.0 kW-6P-B3 model $\mathrm{ABB}$ variable frequency motor, a maximum speed of 980 rpm, a gear metering pump single-rotation displacement of $48.1 \mathrm{cc} / \mathrm{rev}$ and a maximum speed rated flow of $47.0 \mathrm{~L} / \mathrm{Min}$ are adopted. Under the same motor speed, the efficiency of the gear metering pump decreases with the increase in pressure. In accordance with the $85 \%$ efficiency at $10 \mathrm{bar}$, the actual flow rate of the maximum speed can reach 40.0 $\mathrm{L} / \mathrm{min}$, thereby satisfying the requirements of maximum oil flow and pressure. 
According to the technical requirements of oil flow rate of $0.5-3.0 \mathrm{~L} / \mathrm{min}$ and pressure of $5-32 \mathrm{~kg}, \mathrm{C} 2 / 475$ stainless steel gear metering pump, import and export size G1/2, configure QABP90S6A $0.75 \mathrm{~kW}-6 \mathrm{P}-\mathrm{B} 3$ type ABB inverter motor, a maximum speed of $980 \mathrm{rpm}$, a singlerotation displacement of the gear metering pump of 4.75 $\mathrm{cc} / \mathrm{rev}$ and a maximum speed rated flow of $4.6 \mathrm{~L} / \mathrm{min}$ are selected. Under the same motor speed, the efficiency of the gear metering pump decreases with the increase in pressure. In accordance with the efficiency of $75 \%$ at $32 \mathrm{~kg}$, the actual flow rate of the maximum speed can reach 3.45 $\mathrm{L} / \mathrm{min}$, thus satisfying the requirements of maximum oil flow and pressure.

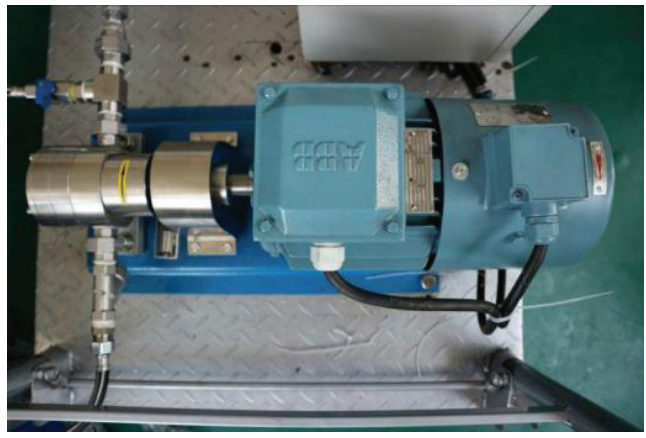

Figure 5 Gear metering pump and variable frequency motor

\subsubsection{Pipe design selection}

The chemical pipeline design guidelines indicate that the pipe diameter must be determined in accordance with the flow rate, nature and pressure loss of the pipeline $e^{[11]}$. The predetermined flow rate method is used to select the pipe diameter which can be calculated as
$\mathrm{D}=\sqrt{\frac{200 \mathrm{Q}_{\text {fluid }}}{3 \pi \mathrm{v}_{\text {fluid }}}}$

where $D$ represents the pipe inner diameter $(\mathrm{mm})$, $Q_{\text {fluid }}$ is the volume flow of the medium in the tube $(\mathrm{L} / \mathrm{min})$, and , $v_{\text {fluid }}$ is the average flow rate of the medium in the tube $(\mathrm{m} / \mathrm{s})$.

The flow rate range of the common medium in the pipeline is recommended, as summarised (see Table 4). The water flow rate is set as $1 \mathrm{~m} / \mathrm{s}$, the oil flow rate is $0.5 \mathrm{~m} / \mathrm{s}$, and the pipe diameter is selected according to the pipeline flow demand of the emulsion direct mixing system, as presented (see Table 5).

\subsubsection{Flow metrer selection}

The deionised water flow range of water path is 10.0-40.0 $\mathrm{L} / \mathrm{min}$; the water path uses a liquid turbine flow metrer, whose model is ECLWGY10CLC2SSN, with DN10 calibre, on-site display, $24 \mathrm{VDC}$ power supply, two-wire 4-20 mA output and G1/2 threaded connection (see Figure 6).

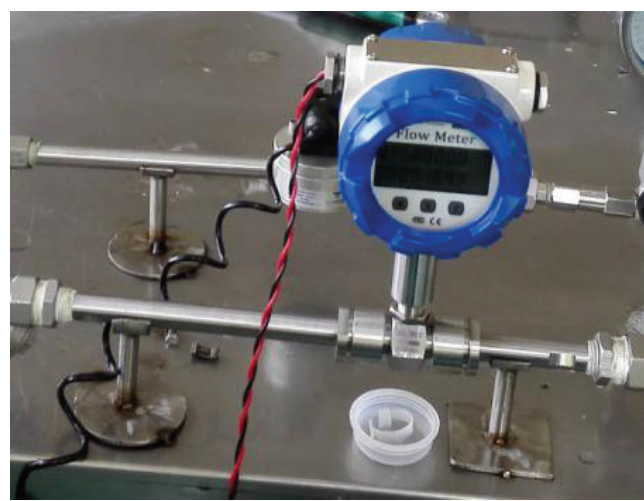

Figure 6 Turbine flow meter for a water pipeline

Table 4 Recommendation velocity range of common fluid

\begin{tabular}{ccc}
\hline medium & Working condition or pipe diameter range & Flow rate range $(\mathrm{m} / \mathrm{s})$ \\
\hline & $0.1 \sim 0.3 \mathrm{MPa}$ & $0.5 \sim 2$ \\
Water and liquid with similar viscosity & $\leq 1 \mathrm{MPa}$ & $0.5 \sim 3$ \\
& $\leq 8 \mathrm{MPa}$ & $2.0 \sim 3.0$ \\
& $\leq 20 \sim 30 \mathrm{MPa}$ & $2.0 \sim 3.5$ \\
Oil and liquid with higher viscosity Viscosi- & $\mathrm{DN} 25$ & $0.5 \sim 0.9$ \\
ty $<0.05 \mathrm{~Pa} \cdot \mathrm{s}$ & $\mathrm{DN} 50$ & $0.7 \sim 1.0$ \\
& $\mathrm{DN} 100$ & $1.0 \sim 1.6$ \\
& $\mathrm{DN} 25$ & $0.3 \sim 0.6$ \\
Oil and liquid with higher viscosity Viscosi- & $\mathrm{DN} 50$ & $0.5 \sim 0.7$ \\
ty $<0.1 \mathrm{~Pa} \cdot \mathrm{s}$ & $\mathrm{DN} 100$ & $0.7 \sim 1.0$ \\
& $\mathrm{DN} 200$ & $1.2 \sim 1.6$ \\
\hline
\end{tabular}

Table 5 Pipeline design and selection of emulsion pipeline direct mixing lubrication system

\begin{tabular}{ccccc}
\hline Pipeline & flow (L/min) & Minimum diameter(mm) & $\begin{array}{c}\text { Maximum } \\
\text { diameter(mm) }\end{array}$ & $\begin{array}{c}\text { Pipe diameter } \\
\text { selection }\end{array}$ \\
\hline Waterway road & $10.0 \sim 40.0$ & 14.57 & 29.13 & DN25 \\
Waterway branch & $5.0 \sim 20.0$ & 10.30 & 20.60 & DN20 \\
Oil road & $0.5 \sim 3.0$ & 4.61 & 11.28 & DN10 \\
Oil road branch & $0.25 \sim 1.5$ & 3.26 & 7.98 & DN8 \\
\hline
\end{tabular}


The turbine flow metrer is based on the principle of torque balance and belongs to the speed flow metrer. This flow metrer has the characteristics of simple structure, lightweight, high precision, favourable repeatability, responsiveness and convenient installation and maintenance. When the fluid flows through the turbine flow sensor housing, the momentum of the fluid causes the blade to have a rotational moment because the blade of the impeller has a certain angle with the flow direction, and the blade rotates after overcoming the friction torque and the fluid resistance. After the torque balance, the rotational speed is stable at a certain degree. The rotation speed is proportional to the flow rate under this condition. The blade is magnetically permeable and is thus in the magnetic field of the signal detector. The rotating blade cuts the magnetic line of force and periodically changes the magnetic flux of the coil. Consequently, the electric pulse signal is induced at both ends of the coil. The signal is amplified and shaped by the amplifier to form a continuous rectangular pulse wave with a certain amplitude, which can be transmitted to the display instrument to show the instantaneous flow or total amount of the fluid. At the upstream end of the turbine flow metrer, at least 20 times of the nominal flow can be installed. For straight pipe lengths of the diameter, the downstream end shall be not less than 5 times the straight pipe section of the nominal diameter.

The rolling oil flow range of the oil passage is $0.5-3.0$ $\mathrm{L} / \mathrm{min}$, and the oil path uses an elliptical gear flow metrer, whose model is ESFD2091, with DN8 calibre, external display instrument, 24 VDC power supply, pulse output and G1/4 threaded connection(see Figure 7). The elliptical gear flow metrer is a typical volumetric flow with a simple structure, reliable use and high accuracy and has no special requirements on the flow field in the inlet and outlet pipes. The viscosity and flow ranges of the measured medium are wide.

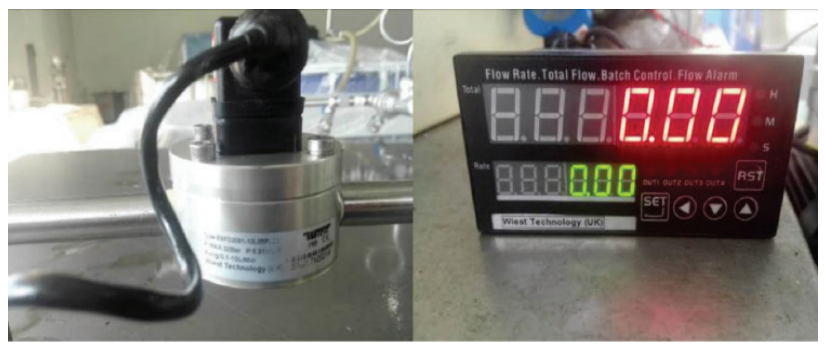

Figure 7 Elliptical gear flow meter for an oil pipeline

The elliptical gear flow metrer uses a liquid flow to push a pair of interlocking gears. Each gear cavity has a fixed volume, and the flow rate of the liquid that flows through each revolution of the gear is constant (see Figure 8 ). The gear speed is extracted. The sensor sends a sync pulse count which can be sent directly to an external receiving component to calculate the fluid flow rate based on the flow metrer for each pulse. The elliptical gear flow metrer can be directly installed on the pipeline, and the flow metrer can be fixed through the pipeline. If the pipeline is a hose, then it can be fixed through the screw hole below; the straight pipe section is required to be larger than 10 times the nominal diameter of the pipeline, and the rear straight section is 5 times the nominal diameter of the pipe.

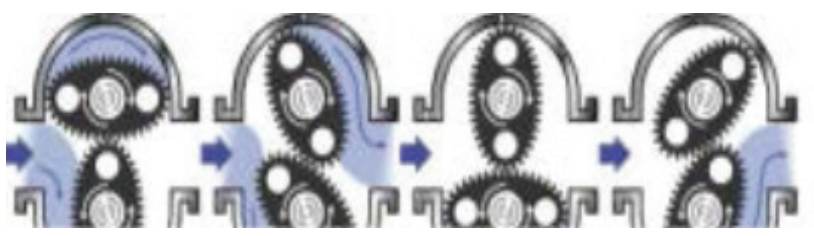

Figure 8 Working mechanism of the elliptical gear flow meter

3.2.5 Pressure gauge selection

A pressure gauge refers to a metrer that uses a spring element as a sensitive component to measure and indicate a pressure higher than the ambient pressure. The pressure gauge is deformed by the elastic deformation of the sensitive component in the watch, and the pressure deformation is transmitted to the pointer by the conversion mechanism of the movement inside the watch. The pointer turns to display the pressure. Sufficient space must be left in accordance with the magnitude of the measured pressure and the pressure change when selecting the gauge range to ensure that the elastic element can work reliably within the safe range of elastic deformation. Therefore, the upper limit of the pressure gauge must be higher than the maximum possible pressure value in the process. When measuring stable pressure, the maximum working pressure must not exceed $2 / 3$ of the upper limit of measurement; when measuring pulsating pressure, the maximum working pressure must not exceed half of the upper limit of measurement; when measuring high pressure, the maximum working pressure must not be more than $3 / 5$ of the upper limit of the measurement. The minimum value of the measured pressure must not be less than $1 / 3$ of the upper limit of the meter measurement.

In the emulsion pipeline direct mixing lubrication system, the water pressure range is 3-10 bar, and the oil pressure range is $5-32$ bar. Therefore, the selected water pressure gauge range is $0-1.0 \mathrm{MPa}$, and the oil pressure gauge range is $0-4.0 \mathrm{MPa}$ (see Figure 9).

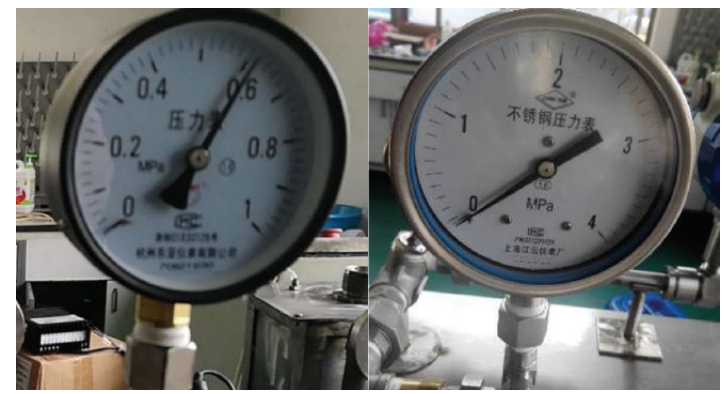

Figure 9 Pressure gauge of water and oil pipeline

3.2.6 Design selection of electric control cabinet

According to the requirement of online adjustment of emulsion flow rate and concentration during the rolling process of the secondary cold rolling mill, the oil and water pumps adopt variable frequency motor, the electric control cabinet is equipped with $380 \mathrm{~V}$ power source to drive the 
variable frequency motor of water and oil pumps, and 24 V DC switching power supply is the water and oil circuit. The flow metrer is powered, and the frequency converter is used to control the rotational speed of the water pump and the oil pump variable frequency motor. In addition, the flow rate of the deionised and rolling oil is adjusted online to realise the online control of the emulsion flow rate and concentration during the rolling process. A physical diagram of the electric control cabinet is displayed in Figure 10 (see Figure10). The main equipment configuration is presented (see Table 6).

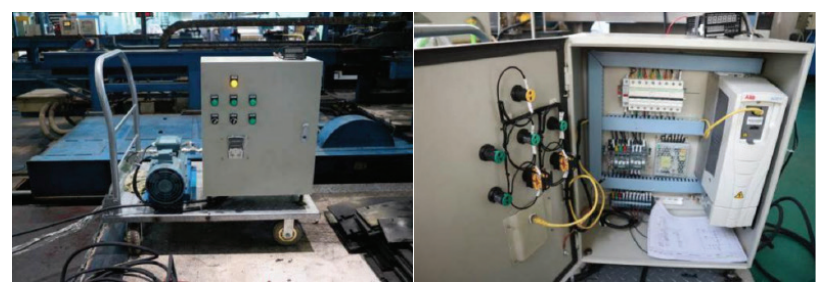

Figure 10 Electric control cabinet

Table 6 Main equipment configuration of electric control cabinet

\begin{tabular}{cccc}
\hline code & name & Model / Specification & Quantity \\
\hline 1 & Distribution Cabinet & $600^{\star} 500^{\star} 250$ & 1 \\
2 & Main switch & IC65 3P 25A & 1 \\
3 & Branch switch & IC65 3P 16A & 2 \\
4 & AC contactor & EASYPACT 2510 & 1 \\
5 & AC contactor & EASYPACT 1810 & 1 \\
6 & Frequency converter & ACS510-01-04A1-4 & 2 \\
7 & Inverter control panel & ABB & 2 \\
8 & Cooling fan & & 1 \\
9 & emergency button & & 1 \\
10 & Knob & & 2 \\
11 & pilot lamp & ABL2REM24045H & 3 \\
\hline
\end{tabular}

4 Engineering application of the emulsion pipeline direct mixing lubrication system of double cold reduction mill

4.1. Equipment renovation and installation of the emulsion pipeline direct mixing lubrication system

According to the equipment conditions of the emulsion pipeline direct mixing lubrication system of double cold reduction mill unit of a tinplate factory, the emulsion of the existing emulsion direct injection system mixing tank is emptied, and deionised water is added and used as the water tank for direct mixing lubrication system of double cold reduction. The emulsion spray pump is used as the water pump of the emulsion pipeline direct mixing lubrication system, and the speed of the water pump is adjusted by the frequency converter to realise the online real-time adjustment of the emulsion flow rate. The emulsion pipeline, flow metrer, pressure gauge and threeway valve equipment are used as the waterway equipment of the direct mixing lubrication system. The connecting hose, waterway check valve and static mixer are added to the emulsion pipeline before the upper and lower spray racks. Thus, the pipeline and equipment of the emulsion mixing tank of the original emulsion direct injection system to the spray rack are fully utilised, and the difficulty and cost of the transformation are reduced. An oil circuit system is added outside the rack to supply rolling oil to the static mixer. The rolling oil is heated to a specified temperature in the fuel tank. The oil pump on the moving trolley is passed through a flow metrer, a pressure gauge, a connecting hose and a check valve. The oil nozzle transports the rolling oil to the static mixer. During the rolling process, the motor speed is adjusted in accordance with the production requirements of the frequency converter to adjust the flow rate of the oil circuit, real-time regulation of the emulsion concentration. Equipment transformation and installation plan for the double cold reduction unit emulsion pipeline direct mixing lubrication system is shown(see Figure 11).

4.2 The emulsions characteristic comparsion of emulsion pipeline direct mixing lubrication system and the traditional direct aplication lubrication system

The emulsion pipeline direct mixing lubrication system and the traditional direct aplication lubrication system are configured with different emulsion concentrations to explain the feasibility of the emulsion pipeline direct mixing lubrication system to replace the traditional direct aplication lubrication system in the field. The corresponding emulsion resistance particle size, laser particle size, ESI and other characteristic parameters are depicted in Figure 12 (see Figure 12).

For the traditonal direct injection system, the emulsion is disposed in the mixing tank, and the rolling oil is cut and dispersed in the water by the blades rotated by an agitator, thereby reducing the particle size of the emulsion and increasing the ESI. Simultaneously, the rolling oil droplets in the emulsion collide with one another in the mixing tank, thus increasing the particle size of the emulsion and decreasing the ESI. Therefore, with the increase in the concentration of the emulsion, the rolling oil in the mixing tank requires additional cutting times for the mixer to form 
the original particle size, and the probability that the rolling oil particles of the emulsion collide with one another increases,thus leading to the increase of emulsification particle size, whereas the ESI decreases. For the emulsion direct mixing lubrication system, under the joint action of the SX static mixer combined with the $2 \#$ atomising oil nozzle, the increase in the emulsion concentration must increase the rolling oil flow rate given the $2 \#$ atomising oil nozzle. The diameter of the nozzle hole is fixed, and the increase in the flow rate of the rolling oil leads to an increase in the pressure of the oil passage. Moreover, the pressure drop of the rolling oil through the atomising oil nozzle is increased, and the shearing predispersion capability of the atomising oil nozzle to the rolling oil is enhanced. The rolling oil can be predispersed in deionised water with small particles. Therefore, with the increase in emulsion concentration, the particle size of the emulsion decreases, and ESI increases. The emulsion and tank mixing and their mixing emulsion characteristics exhibit the opposite trend with the emulsion concentration. When the emulsion concentration is low, the direct mixing of the pipeline is improved with respect to the mixing tank. Thus, the lubrication performance is improved, and the stability is lowered. When the emulsion concentration is high, the lubricating performance of the direct mixing of the pipeline with respect to the mixing tank is lowered, and the stability is improved. Overall, the emulsion pipeline direct mixing lubrication system has the same range of resistance method particle size, laser method particle size and ESI as the traditional direct aplication lubrication system.Therefore, through the optimal selection of key equipment, such as static mixer and atomising oil nozzle, for the emulsion pipeline direct mixing lubrication system, the emulsion pipeline direct mixing system can satisfy the requirements of emulsion performance well on the on-site production of secondary cold rolling mills.

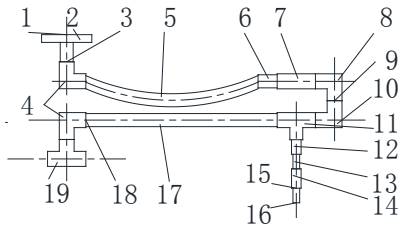

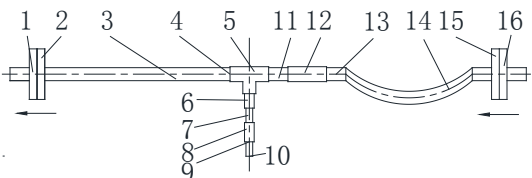

b

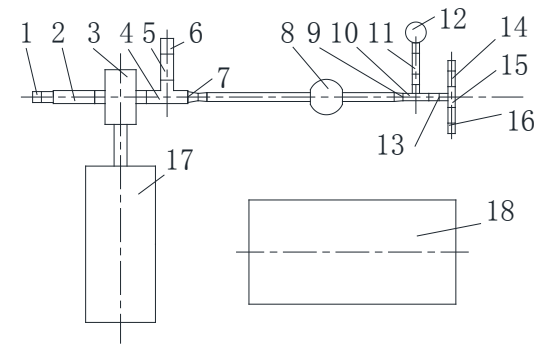

(a) Upper static mixer pipeline transformation plan.(1)Water intake,(2)Flange,(3)Inner and outer wire joint G3/4,(4)Inner and outer wire joint elbow,(5)Hose,(6)Interface G3/4,(7)Check valve,(8)Outer wire elbow,(9)External wire joint G3/4,(10)Inner and outer wire joint elbow,(11)Reducing tee,(12)oil-atomising sprayer,(13)Interface G3/4,(14)One-way valve,(15)Inner and outer wire joint G1/4,(16)Oil inlet (connected to G1/4 hose),(17)Upper static mixer,(18)Inner and outer wire joint G3/4,and(19)Emulsion outlet.( b) Lower static mixer pipeline transformation installation plan. (1)Emulsion outlet (Go down the spray rack), (2)Flange, (3)Lower static mixer,(4)Inner and outer wire joint G3/4,(5)Reducing tee,(6)oil-atomising sprayer,(7)Interface G1/4,(8)One-way valve,(9)Interface G1/4,(10)Oil inlet connected to the G1/4 hose $10 \mathrm{~m},(11)$ Interface G3/4,(12)One-way valve,(13)Interface G3/4,(14)hose 800 mm,(15) Flange,(16)Hot water inlet. (c) Oil circuit equipment installation plan. (1)Oil inlet hose,(2)Filter,(3)Gear pump,(4)Three-way valve,(5) Ball valve,(6)Return hose,(7)Interface G1/2,(8)Flow metrer,(9)Interface G1/4,(10)Three-way valve,(11)Needle valve,(12)Pressure gauge,(13)Interface G1/4,(14)Ball valve,(15)Three-way valve,(16)Oil hose,(17)Inverter motor,(18)Electric control cabinet

Figure 11 Modification and installation position of the emulsion pipeline direct mixing lubrication system
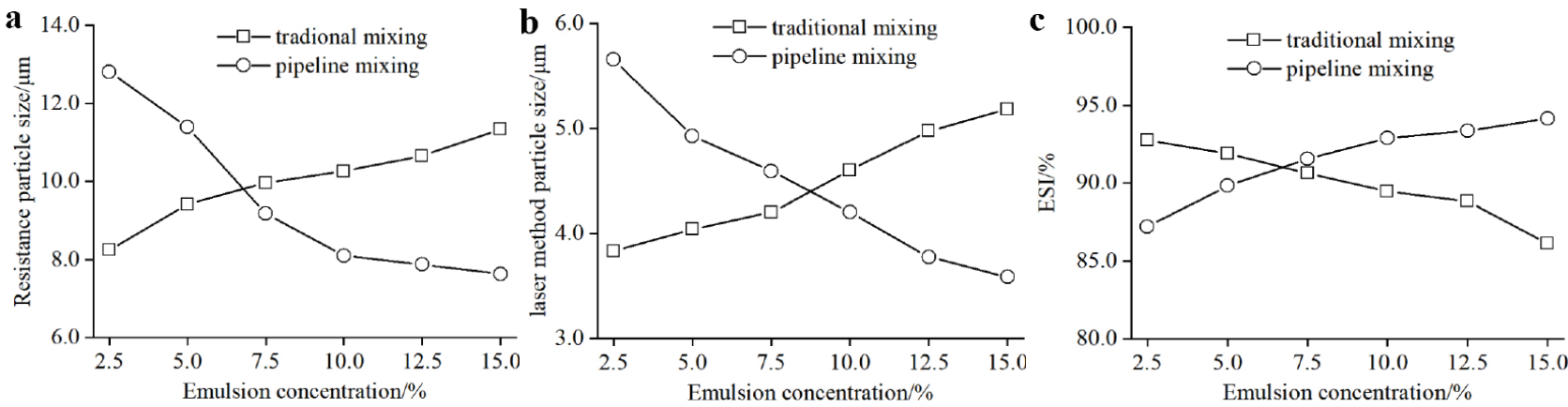

(a) Resistance particle size. (b) Laser particle size. (c) Emulsion ESI.

Figure 12 Comparison of traditional mixing and pipeline mixing by mixing emulsion property

4.3 Field application effect of emulsion pipeline direct mixing lubrication system

A 1220 double cold reduction unit of a steel enterprise with a set of emulsion pipeline for direct mixing lubrication is adopted by using the design scheme developed in this study to improve the rolling stability and product quality 
of the unit, reduce the rolling energy consumption and fuel consumption cost and apply it to production practices. After applying the lubrication system and after 6 months of on-site production statistics, the average fuel consumption per ton of steel is reduced by $9.6 \%$, and the overall cost of rolling energy consumption and fuel consumption per ton of steel is reduced by $10.7 \%$. Furthermore, the thickness of the strip section is reduced by $19.3 \%$, and the incidence of plate shape quality defects is decreased by $25.6 \%$. These conditions create considerable economic benefits for the unit. To analyse the usage effect of the emulsion pipeline direct mixing lubrication system, the TH580 steel grade of the typical specification is selected on the site of trouble cold reduction, and the conventional direct injection and the emulsion pipeline direct mixing lubrication system are used for on-site rolling test. During the rolling process, the flow rate and concentration of the emulsion in the traditional direct aplication lubrication system are fixed. The direct mixing lubrication system of the emulsion is set in accordance with the change in the rolling speed of the emulsion flow and concentration comprehensive optimisation technology. In addition,authors compared the traditional direct aplication lubrication system with the emulsion pipeline direct mixing lubrication system, analysing the rolling pressure, energy consumption, oil consumption and total fuel consumption cost. The steel plate thickness and shape measurement data are also comparatively analysed. The thickness and shape quality of the traditional direct injection lubrication system in the cold rolling mill and the direct hybrid lubrication system of the emulsion pipeline fluctuate. The rolling process parameters are listed (see Table 7).

Table 7 Rolling parameters of field experiment coils of double cold rolling mill

\begin{tabular}{ll}
\hline Steel grade & TH580 \\
\hline Strip width $B / \mathrm{m}$ & 0.847 \\
Inlet thickness $H / \mathrm{mm}$ & 0.201 \\
Outlet thickness $h / \mathrm{mm}$ & 0.150 \\
Entrance yield strength $\sigma_{s 0} / \mathrm{MPa}$ & 320 \\
Export yield strength $\sigma_{s 1} / \mathrm{MPa}$ & 580 \\
Post-tension stress $\sigma_{0} / \mathrm{MPa}$ & 118 \\
Pre-tension $\sigma_{1} / \mathrm{MPa}$ & 168 \\
\hline
\end{tabular}

4.3.1 Comparison of energy consumption and fuel consumption parameters

The TH580 steel grade which adopts the traditional direct aplication lubrication system and the emulsion pipeline direct mixing lubrication system obtains disparate result, such as the emulsion flow setting value, emulsion concentration setting value, rolling pressure, rolling energy consumption and fuel consumption. (see Figure 13).
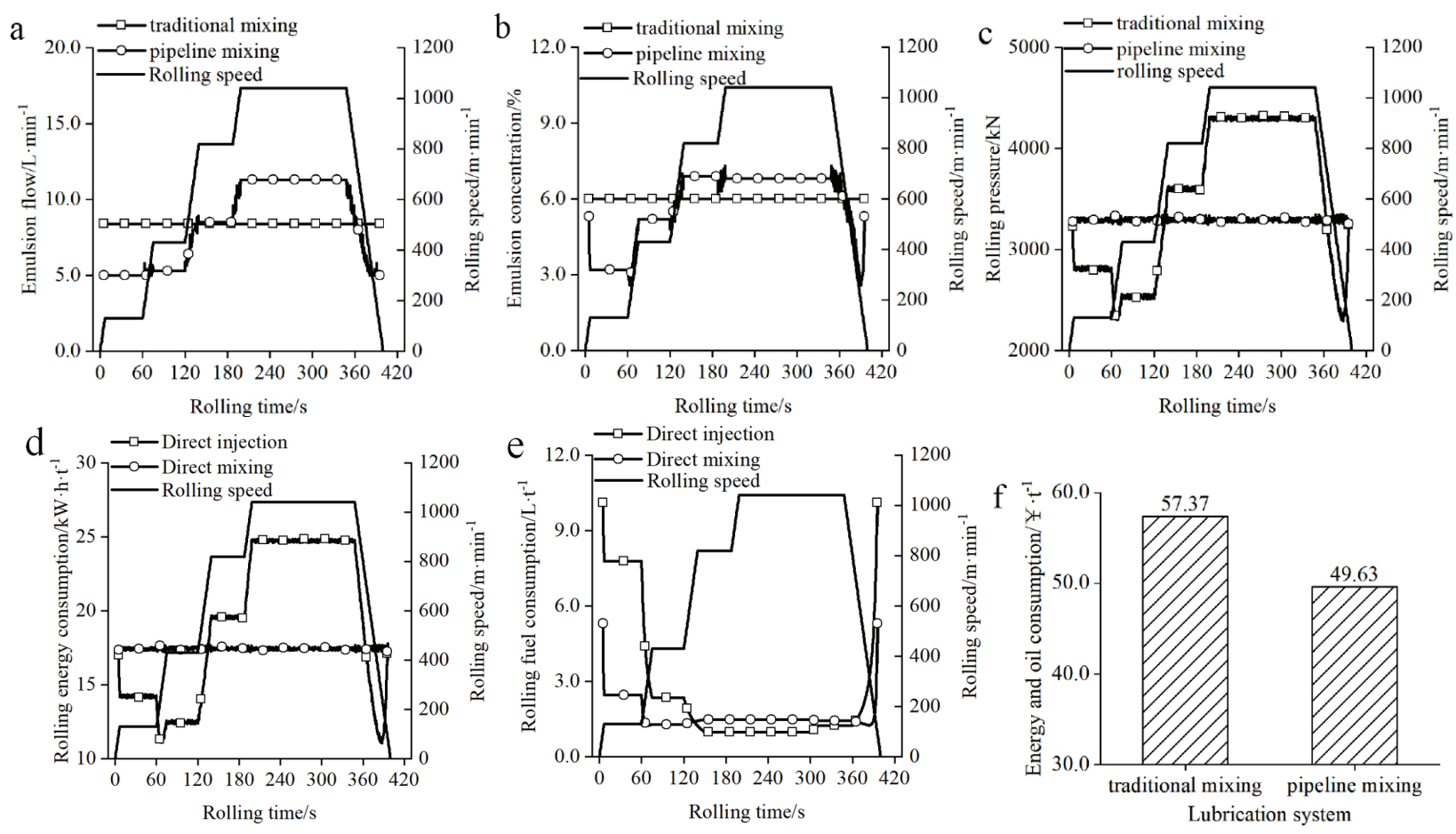

(a) Emulsion flow.(b) Emulsion concentration.(c) Rolling pressure.(d) Rolling energy consumption.(e) Rolling fuel consumption. (f) Rolling energy consumption and total fuel consumption cost.

Figure 13 Comparison of the TH580 steel rolling parameters between traditional direct application and the emulsion pipeline direct mixing lubrication system.

Figure 13 displays that the rolling pressure fluctuation is reduced from $1780 \mathrm{kN}$ to $50 \mathrm{kN}$ at different rolling speeds after applying the emulsion pipeline direct mixing lubrication system of double cold reduction mill unit (see Figure 13). The stability of the rolling pressure is significantly improved, whereas the total rolling energy and 
fuel consumption are considerably reduced.

4.3.2 Strip thickness and shape quality comparison

During the on-site rolling test of double cold reduction, the thickness and shape of the strip are measured by the thickness gauge of the rack outlet and the shape metrer, respectively. The thickness and shape data of the on-site rolling test are derived, and the thickness and plate are

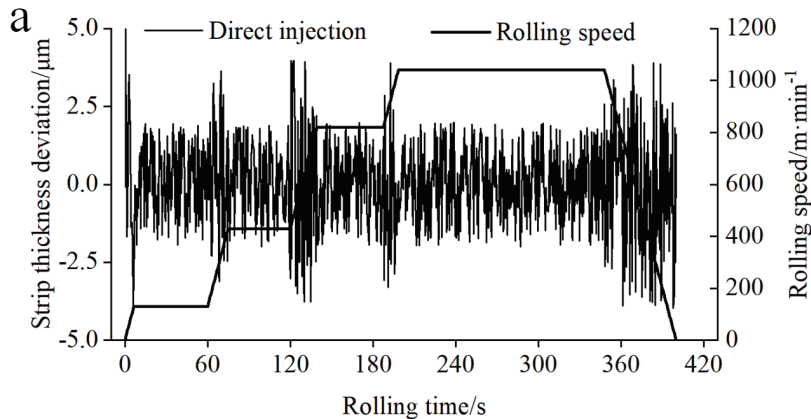

(a) Traditional direct injection compared. The shape fluctuation, the traditional direct injection lubrication system and the emulsion pipeline direct mixing lubrication system corresponding to the strip thickness deviation comparison are presented in Figure 14 (see Figure 14). Moreover, the strip shape value comparison is illustrated in Figure 15 (see Figure 15), and the strip shape quality is demonstrated in Figure 16 (see Figure 16).

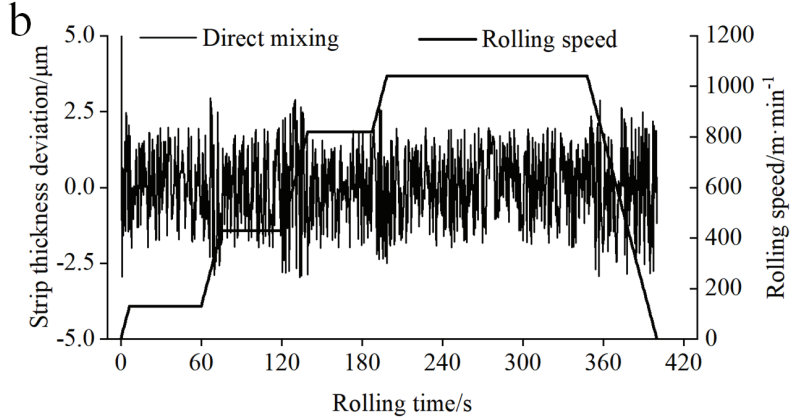

(b) Direct mixing

Figure 14 Comparison of the TH580 steel thickness deviation between traditional direct application and direct mixing lubrication system

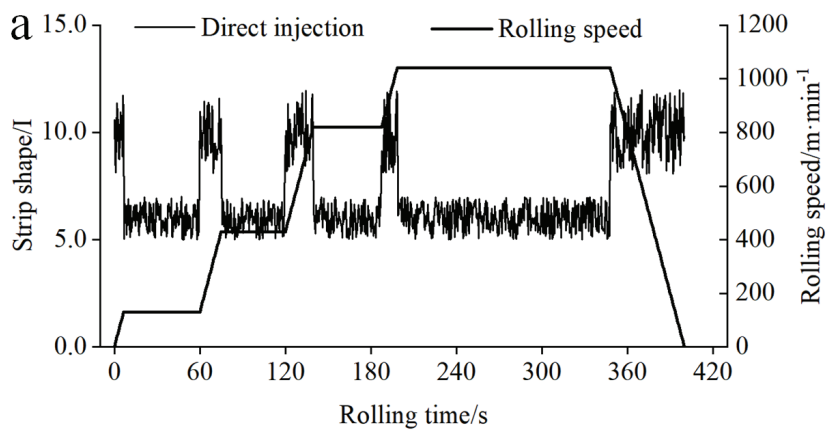

(a) Traditional direct injection

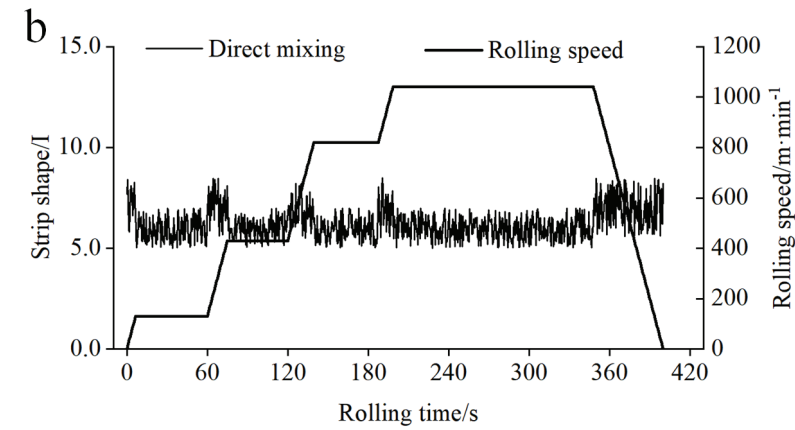

(b) Direct mixing

Figure 15 Comparison of the TH580 steel flatness between traditional direct application and direct mixing lubrication system

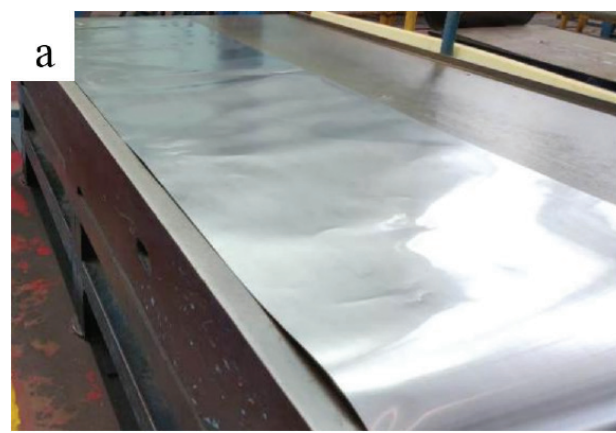

(a) Traditional direct injection

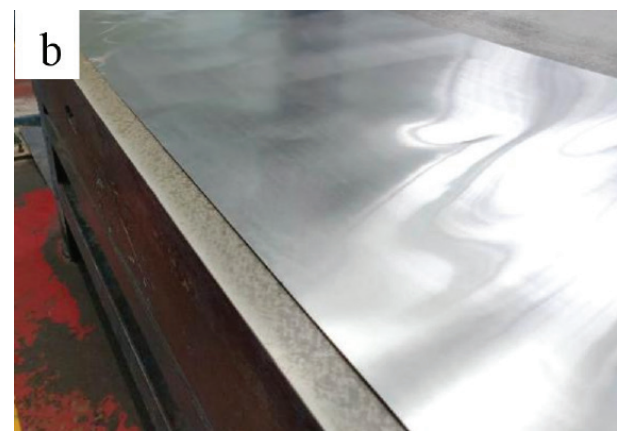

(b) Direct mixing

Figure 16 TH580 steel flatness with traditional direct application and direct mixing lubrication system

Figures 14-16 depict that the flow rate and concentration of the emulsion in the traditional direct aplication lubrication system remain unchanged with the rolling speed; consequently, the rolling pressure fluctuates significantly during the lifting speed, and the strip thickness deviation and plate shape value fluctuate more than those in the steady speed stage. After applying the direct mixing lubrication system of the emulsion pipeline, the thickness deviation of the strip and the fluctuation of the plate shape are reduced with the decrease in the rolling 
pressure fluctuation during the lifting speed. Furthermore, the thickness stability of the strip is improved, and the plate shape value is lowered.

\section{Conclusion}

(1) A direct mixing lubrication system suitable for emulsion pipeline is developed by fully considering the equipment and process characteristics of double cold reduction and analysing the technological characteristics of the traditional emulsion direct injection lubrication system. The selection of key components of the emulsion pipeline direct mixing lubrication system is completed in eight aspects, namely, selecting a static mixer and an oil mist nozzle, water and oil pump designs, pipeline design, flow metrer, pressure gauge and electric control cabinet. And forms a complete set of the emulsion pipeline direct mixing lubrication system of double cold reduction mill, which is applied to the production practice of a 1220 double cold reduction unit.

(2) A comparison of the emulsion characteristics of the emulsion pipeline direct mixing lubrication system and the traditional direct injection lubrication system with tank mixing shows that their characteristics have opposite trends with emulsion concentration. When the emulsion concentration is low, the lubricating properties of the pipeline lubricants is directly mixed relative to the mixing tank mixing emulsion are improved and the stability is reduced; when the emulsion concentration is high, the lubricating properties of lubricants are reduced and the stability is improved. Overall, the range of resistance method particle size, laser method particle size and ESI of direct mixing of the pipeline relative to mixing mixing emulsion in the mixing tank is equivalent and is adapted to the demand for the emulsion performance in the on-site production of double cold reduction mill.

(3) With the emulsion pipeline direct mixing lubrication system of double cold reduction mill, after field application of 1220 double cold reduction mill and after 6 months of on-site production data statistics, the average fuel consumption per ton of steel is reduced by $9.6 \%$, and the energy consumption per ton of steel is also reduced. The comprehensive cost of fuel consumption is reduced by $10.7 \%$, and the length of the strip thickness of the strip section is reduced by $19.3 \%$. Moreover, the incidence of sheet shape quality defects is reduced by $25.6 \%$. These conditions create considerable economic benefit for the unit.

Author Contributions: Zhen-hua BAI contributed to the conception of the study; Hang-zhe DONG performed the experiment; Ya-zhen ZHANG contributed significantly to analysis and manuscript preparation; Wan-tong $\mathrm{HU}$ performed the data analyses and wrote the manuscript; Yan-yan ZHANG helped perform the analysis with constructive discussions.
Conflict of Interest: The authors declare that there is no conflict of interest regarding the publication of this paper.

Acknowledgments: This work is supported by the Natural Science Foundation of Hebei Province (Grant No. E20160203385) and the Heavy Machinery Collaborative Innovation Program (Grant No. ZX01-20140400-05). A few experiments were made in Baosteel Tinplate Plant. The authors gratefully acknowledge the technical support of Baosteel.

\section{References}

[1] BAI Zhen-hua; SONG He-chuan. Research development of double cold reduction equipment and process. Journal of Plasticity Engineering, 2016, 23(06): 87-93.

[2] ZHANG Hong-bo; FENG Xiao-yong. Research progress and application status of double reduced materials for tin-plate. Hebei Metallurgy, 2017, (04): 1-5.

[3] JI Jiang; HU Hong. Development and application of skin pass and double cold-reduced mill processing for high quality ultra-thin uncoated tin-plated sheet. Steel Rolling, 2018, 35(01): 49-51.

[4] CUI Ya-ya; LI Bo-yang. Comprehensive optimization setting of emulsion flowrate and concentration for double cold reduction mill. Iron and Steel, 2018, 53(02): 40-44.

[5] WEI Li-qun; DAI Zhi-fang. Research of vibration and strategy in high speed cold-rolling mill. Journal of Mechanical Engineering, 2016, 52(11): 88-94.

[6] Kimura Y; Fujita N. High-speed rolling by hybridlubrication system in tandem cold rolling mills. Journal of Materials Processing Technology, 2015, 216: 357-368.

[7] Das P K; Legrand J. Drop Breakage Model in Static Mixers at Low and Intermediate Reynolds Number. Chemical Engineering Science, 2005, 60(1): 231-238.

[8] LI Xiu-jun; CUI Ya-ya. Model of plate-out oil film thickness on strip surface of direct application system in double cold rolling and its influence factors. Journal of Plasticity Engineering, 2018, 25(4): 285-290.

[9] WANG Xiu-gang; GUO Wa-li. Experimental and numerical study on liquid-liquid dispersion in static mixer. Journal of Chemical Industry and Engineering, 2012, 63(3): 767774.

[10] Lobry E; Theron F. Turbulent liquid-liquid dispersion in SMV static mixer at high dispersed phase concentration. Chemical Engineering Science, 2011, 66(23): 5762-5774.

[11] XU Bao-dong. Chemical Pipeline Design Manual, 1st ed. Chemical Industry Press: Beijing, China, 2011, 7-8. 